\title{
Identification and characterization of a novel isoform of the vesicular $\gamma$-aminobutyric acid transporter with glucose-regulated expression in rat islets
}

\author{
A T Suckow ${ }^{1,2}$, I R Sweet ${ }^{3}$, B Van Yserloo ${ }^{3}$, E A Rutledge ${ }^{3}$, T R Hall ${ }^{3}$, M Waldrop' and \\ S D Chessler ${ }^{1}$ \\ ${ }^{1}$ Department of Medicine, University of California, San Diego, Leichtag Biomedical Research Building, 9500 Gilman Drive MC 0726, La Jolla, California 92093-0726, USA \\ ${ }^{2}$ Biomedical Sciences Graduate Program, University of California, San Diego, 9500 Gilman Drive, La Jolla, California 92093, USA \\ ${ }^{3}$ Robert H Williams Laboratory, Department of Medicine, Box 357710, University of Washington, Seattle, Washington 98195-7710, USA
}

(Requests for offprints should be addressed to S D Chessler; Email: schessler@ucsd.edu)

\begin{abstract}
Pancreatic islets are unique outside the nervous system in that they contain high levels of the inhibitory neurotransmitter $\gamma$-aminobutyric acid (GABA), synthesized by the enzyme glutamic acid decarboxylase (GAD). Since the role that GABA plays in the islet and the mechanisms whereby the two major GAD isoforms (GAD65 and GAD67) function as diabetes-associated autoantigens are unknown, continued characterization of the islet GAD-GABA system is important. We previously demonstrated that the GABA and glycine transporter vesicular inhibitory amino acid transporter (VIAAT also known as VGAT) is present in rat islets. Here we identify a novel 52 kDa variant of VIAAT in rat islets: VIAAT-52 (V52). V52 is an amino-terminally truncated form of VIAAT (V57) that likely results from utilization of a downstream start site of translation. V57 and V52 display different patterns of post-translational modification and cellular expression. Our results have indicated that islet content of V52, but not V57, is responsive to changes in glucose concentration and other extracellular conditions. VIAAT is expressed in the islet $\alpha$ cells, but there have been conflicting findings regarding the presence of VIAAT in the $\beta$ cells. Here we have also provided additional evidence for the presence of VIAAT in islet $\beta$ cells and show that the $\beta$ cell line INS-1 expresses V57. V52 may be better adapted than V57 to the unique rat $\alpha$ cell GAD-GABA system, which lacks GAD65 and in which VIAAT traffics to secretory granules rather than just to synaptic microvesicles.
\end{abstract}

Journal of Molecular Endocrinology (2006) 36, 187-199

\section{Introduction}

A distinctive feature of pancreatic islets is that they synthesize and store $\gamma$-aminobutyric acid (GABA). Despite much work, though, the role of GABA in the endocrine pancreas remains unknown (Satin \& Kinard 1998, Chessler \& Lernmark 2000). In the central nervous system, GABA is the major inhibitory neurotransmitter. In the islets, it probably also functions as an intercellular signaling molecule, perhaps - as there is evidence to suggest - as a paracrine or autocrine regulator of insulin or glucagon secretion (Chessler \& Lernmark 2000, Braun et al. 2004a,b). Recent evidence suggests that a second inhibitory neurotransmitter, glycine, also plays a role in islet function (Gammelsaeter et al. 2004).

Characterization of the cellular GABA signaling machinery in islets will likely yield important insights into the role of GABA in islet function. The GABA system is also of great interest because the enzymes that catalyze the synthesis of GABA - glutamic acid decarboxylase (GAD)65 and GAD67, the two major isoforms of GAD - are key autoantigens associated with human (in the case of GAD65) and NOD mouse (in the case of both GAD65 and GAD67) autoimmune diabetes (Elliott et al. 1994, Lernmark 1996). The interactions of GAD65 and GAD67 with other protein constituents of the islet GAD-GABA system may help mediate the intracellular trafficking of the two enzymes, their characteristic association with microvesicles, and, perhaps, therefore, their distinctive ability to function as autoantigens (Solimena 1998).

In the central nervous system, the vesicular inhibitory amino acid transporter (VIAAT) is a key component of the GABAergic and glycinergic signaling machinery. VIAAT is a transmembrane protein that utilizes a proton electrochemical gradient to transport GABA and glycine into synaptic vesicles where they are stored prior to release (Gasnier 2004). Due to the importance of characterizing the pancreatic islet GAD-GABA system, we previously investigated the distribution of VIAAT in rat islets. We found that the rat islet mantle (the islet 
periphery, where the $\alpha$ cells are found) harbors a unique GAD-GABA signaling apparatus, characterized by the presence of GAD67, GABA, and VIAAT but not GAD65 (Chessler et al. 2002). Lower levels of VIAAT were also detected in the rat islet $\beta$ cells, which contain GAD65 (Chessler et al. 2002). Hayashi et al. (2003a) subsequently confirmed the presence of VIAAT in the rat islet mantle, detecting none in the islet $\beta$ cells. Unexpectedly, VIAAT was found to localize to the glucagon-containing secretory granules rather than to the synaptic-like microvesicles also present in islet $\alpha$ cells. In contrast, Gammelsaeter et al. (2004) identified VIAAT in both secretory granules and microvesicles in rat islet $\alpha$ cells and also detected comparatively low levels in the $\beta$ cells.

VIAAT is a $57 \cdot 4 \mathrm{kDa}$ protein (V57). A phosphorylated form $\left(\mathrm{V} 57^{\prime}\right)$ that migrates more slowly by SDS-PAGE is observed in brain tissue extracts (Bedet et al. 2000). We found that islet extracts, in contrast to neural tissue, contain little or no V57' (Chessler et al. 2002). Unexpectedly, immunoblotting also revealed a second, more rapidly migrating form of the protein in islet and brain extracts. This form was predominant in islet cell extracts and has an apparent molecular weight of $52.5 \mathrm{kDa}$ (V52). Hayashi et al. (2003a), using a novel antibody that may have a relatively lower affinity for V57, observed only an $\sim 52 \mathrm{kDa}$ VIAAT band in rat islet extracts and $\alpha$ TC6 cells, while both V57 and V52 were detected in brain. The $\sim 52 \mathrm{kDa}$ form of VIAAT is present in low abundance in rat and human brain tissue extracts and is detected, as well, in purified synaptic vesicles and rat pineal gland extracts (Takamori et al. 2000, Chessler et al. 2002, Jin et al. 2003, Echigo \& Moriyama 2004). COS-7 and tsA201 cells transfected with different VIAAT cDNA constructs also express an $\sim 52 \mathrm{kDa}$ form of the protein along with the more abundant $57 \mathrm{kDa}$ form (Dumoulin et al. 1999, Takamori et al. 2000). Using rat and human brain extracts, we found that the $52.5 \mathrm{kDa}$ VIAAT proteins from neural and islet cells co-migrate by SDS-PAGE and are therefore most likely identical (Chessler et al. 2002). Similar data suggest that V52 from islet and brain extracts is identical to that synthesized after VIAAT cDNA is either transfected into tsA201 cells or introduced into reticulocyte lysates for in vitro transcription and translation (Takamori et al. 2000, Chessler et al. 2002).

Due to the relatively low abundance of V52 in neural tissue as compared with islet cells, evidence pointing to the existence of a $52 \mathrm{kDa}$ isoform of VIAAT has been previously overlooked. Here, we have identified V52 as a novel variant of VIAAT truncated at the amino terminal end and differentially modified. We have also shown that V57 is present in INS-1 cells and have used immunohistochemistry to provide further evidence of the presence of VIAAT in islet $\beta$ cells.
Herein, we have also tested the hypotheses (1) that V52 is formed by utilization of an alternate start site of translation and (2) that its level of expression is independent of that of V57 and responsive to glycemic conditions.

\section{Materials and methods}

\section{Antibodies}

The antibody referred to as VT/510 is an affinitypurified antibody to the carboxyl terminus of VIAAT (Chemicon, Temecula, CA, USA). VT/75 (Synaptic Systems, Göttingen, Germany) is an affinity-purified antibody to VIAAT residues 75-87. A monoclonal antibody raised against the same peptide (M-VT/75) was also purchased from Synaptic Systems. VT/75 and M-VT/75 are well characterized and have been used extensively to detect VIAAT in neural and testicular tissue, to specifically identify inhibitory synapses and to immunopurify VIAAT-carrying microvesicles (see, for example: Geigerseder et al. 2003, Prange et al. 2004, Chih et al. 2005, Saito et al. 2005). VT/17 was made to our specifications by Alpha Diagnostic, Inc. (San Antonio, TX, USA) in rabbit hosts by coupling a peptide representing VIAAT residues 17-30 (CSNKSQAKVS GMFAR) to keyhole limpet hemocyanin. In preliminary immunoblotting experiments, $\mathrm{VT} / 17$ was found to recognize the $57 \mathrm{kDa}$ VIAAT band in rat brain and islets but did not detect a $57 \mathrm{kDa}$ protein in three tissues previously shown not to express VIAAT: rat kidney, liver and skeletal muscle (McIntire et al. 1997). Preimmune serum from the same rabbit used to generate VT/17 was retained for use as a negative control. VT/17 was not suitable for immunohistochemistry using either frozen or paraffin-embedded tissues. A monoclonal antibody to glyceraldehyde-3phosphate dehydrogenase was from Chemicon and another to the amino terminus of GAD65 was a kind gift from Dr Åke Lernmark (Hampe et al. 2001). Rat brain extract was purchased from Stressgen (Victoria, BC, Canada).

\section{In vitro expression of VIAAT}

Transcription and translation of VIAAT cDNA to produce radiolabeled VIAAT in rabbit reticulocyte lysates was carried out as described previously (Chessler et al. 2002). The Quickchange site-directed mutagenesis kit (Stratagene, La Jolla, CA, USA) was used to introduce point mutations into the VIAAT cDNA. A $\mathrm{T}>\mathrm{C}$ substitution at cDNA position 2 was used to generate mutation M1T, and M31 L was created by changing $\mathrm{A}>\mathrm{C}$ at position 91 and $\mathrm{G}>\mathrm{A}$ at position 93 . M1T-6 xHis was made by utilizing PGR to introduce a $6 \mathrm{xHis}$ tag on the $3^{\prime}$ end of VIAAT M1T: VIAAT M1T 
was amplified with the primers GACCAAGCTTGCG GCAAC $\left(5^{\prime}\right)$ and TTAATGATGATGATGATGATG GTCATCGGCGTTGGTT $\left(3^{\prime}\right)$ and the resulting product then cloned into PCRII-Topo (Invitrogen, Carlsbad, CA, USA). Full-length sequencing of all plasmid inserts confirmed that the constructs were as expected. 6 xHis-tagged V52 was purified using His-Select nickel affinity gel (Sigma, St Louis, MO, USA). Purified protein was sent to the Harvard Microchemistry and Proteomics Facility (Cambridge, MA, USA) for N-terminal sequencing after being prepared and blotted onto Sequi-Blot PVDF membrane (Bio-Rad Laboratories, Hercules, CA, USA) as specified by the microsequencing facility.

\section{Islet preparation}

Islets were isolated from the pancreata of diabetesresistant (DR) BioBreeding (BB) rats (Bieg et al. 1998) by digestion with Liberase (Roche Molecular Biochemicals, Indianapolis, IN, USA) followed by Optiprep (Nycomed, Oslo, Norway) gradient purification as previously described (Chessler et al. 2002). Isolated islets were handpicked in Hank's balanced salt solution (Invitrogen, Carlsbad, CA, USA). They were then either rinsed with phosphate-buffered saline (PBS) and lysed or cultured in RPMI (Invitrogen) with 3, 10 or $20 \mathrm{mmol} / \mathrm{l}$ glucose and supplemented with $10 \%$ fetal bovine serum. Islets were lysed at $4{ }^{\circ} \mathrm{C}$ in Novex NuPage sample buffer (Invitrogen) or SDS boiling buffer (5\% SDS, 10\% glycerol and $60 \mathrm{mmol} / \mathrm{l}$ Tris, $\mathrm{pH} 6 \cdot 8$; four islets/ $\mu \mathrm{l}$ ) and the extracts were either boiled for $4 \mathrm{~min}$ or heated for $7 \mathrm{~min}$ at $70^{\circ} \mathrm{C}$. At the time of islet lysis, detergent buffers were supplemented with a protease inhibitor cocktail (P8340; Sigma) and $1 \mathrm{mmol} / \mathrm{l}$ phenylmethylsulfonyl fluoride. To test lysis in non-ionic detergent, islets were incubated for $30 \mathrm{~min}$ in a solution of $1 \%$ Nonidet P40 (NP-40) in PBS, and the nuclei and other debris pelleted by spinning for $10 \mathrm{~min}$ at $10000 \mathrm{~g}$. Islets not immediately lysed were stored frozen at $-80{ }^{\circ} \mathrm{C}$.

\section{INS-1 cells}

INS-1 cells were a kind gift from Christopher Rhodes (Pacific Northwest Research Institute, Seattle, WA, USA). INS-1 cells from the Rhodes laboratory have been successfully used by that laboratory and others as a model of $\beta$ cell biology in the publications cited here and others (Dickson et al. 2001, Wrede et al. 2002, 2003, Lingohr et al. 2003). One of us (I R S) has performed perifusion experiments using the INS-1 that we received and that were in the same passage number range as the cells used for the experiments described herein (Sweet et al. 2002). These perifusion experiments demonstrated appropriate responses to glucose and epinephrine and as well as sulfonylurea (glibenclamide) binding (Sweet et al.
2002). Using an insulin ELISA (Crystal Chem. Inc., Downers Grove, IL, USA), we have periodically evaluated glucose-stimulated insulin secretion using static culture and similarly determined that the cells had maintained glucose responsiveness (data shown herein and other data not shown). Immunhistochemistry reveals uniform insulin expression by this INS-1 line, with all cells expressing insulin (data shown herein and other data not shown).

INS-1 cells were cultured in medium with $11 \mathrm{mM}$ glucose as described (Sweet et al. 2004). Cell extracts were prepared in the same manner as islet extracts. Protein content of cell and islet extracts was determined with the DC protein assay (Bio-Rad) to ensure that equal amounts of protein were loaded into gel lanes.

\section{Subcellular fractionation}

INS-1 cells were fractionated using the method of Clift-O'Grady et al. (1998). Briefly, cells were pelleted at $800 \boldsymbol{g}$ for $5 \mathrm{~min}$, resuspended in budding buffer $(38 \mathrm{mM}$ potassium glutamate, $38 \mathrm{mM}$ potassium gluconate, $20 \mathrm{mM}$ 4-morpholinepropanesulfonic acid, pH 7.2, $5 \mathrm{mM}$ reduced glutathione, $5 \mathrm{mM}$ sodium carbonate and $2.5 \mathrm{mM}$ magnesium sulfate) and pelleted again at $800 \boldsymbol{g}$ for $5 \mathrm{~min}$. Cells were resuspended in budding buffer with protease inhibitors (Roche Molecular Biochemicals) and homogenized using a Balch-designed cell cracker (European Molecular Biology Laboratory, Heidelberg, Germany). Trypan blue exclusion was used to ensure efficient homogenization. The resulting homogenate was sedimented in an SS34 rotor at $1000 \boldsymbol{g}$ for $5 \mathrm{~min}$ to obtain a low speed supernatant (S1). S1 supernatants were then sedimented at $27000 \boldsymbol{g}$ for $35 \mathrm{~min}$ to generate a high speed supernatant (S2) and pellet (P2). To verify exclusion of secretory granules from the S2 supernatant, the supernatant was fractionated by velocity gradient centrifugation (Clift-O'Grady et al. 1998) and the fractions evaluated for chromogranin A content by western blot analysis. The S2 supernatant utilized for the experiments shown herein contained synaptophysin, a marker of synaptic-like microvesicles and, as expected, lacked chromogranin A, which instead was found in P2 (A T Suckow, unpublished observations). Tissue extract from BB (DR) rat brains and crude synaptic vesicle preparations were made as previously described (Jin et al. 2003).

\section{Immunofluorescence}

Cells were seeded on four-well chamber slides (BD Biosciences, San Jose, CA, USA) coated with poly-Llysine and allowed to grow for $48 \mathrm{~h}$. They were fixed in a $4 \%$ paraformaldehyde solution for $1 \mathrm{~h}$, washed twice in $1 \times$ PBS and permeabilized and blocked with PBS containing $0 \cdot 2 \%$ Triton-X-100 and $3 \%$ bovine serum 
albumin (BSA) for $1 \mathrm{~h}$. Cells were then incubated with a 1:200 dilution of mouse anti-insulin and of rabbit VIAAT antibody for $1 \mathrm{~h}$. After incubation, cells were washed three times with PBS and incubated with a 1:200 dilution of AlexaFluor568 anti-mouse IgG conjugate, a 1:200 dilution of AlexaFluor488 anti-rabbit IgG and a 1:1000 dilution of To-pro 3 (Molecular Probes, Eugene, OR, USA). Confocal microscopy was performed on an FV1000 confocal microscope configured with an Argon/Krypton laser (488 and $568 \mathrm{~nm}$ excitation lines) (Olympus, Melville, NY, USA).

\section{Insulin secretion assays}

Cells were grown on 12-well plates $48 \mathrm{~h}$ prior to measuring insulin then washed twice with Krebs-Ringer bicarbonate buffer containing $0 \cdot 2 \%$ BSA and $2.5 \mathrm{mM}$ glucose. They were then incubated for $30 \mathrm{~min}$ in this buffer. After incubation, this solution was removed and replaced with Krebs-Ringer containing either $2.5 \mathrm{mM}$ glucose or $25 \mathrm{mM}$ glucose. Cells were incubated for $2 \mathrm{~h}$, the media were removed and insulin content was measured using a rat insulin ELISA kit (Crystal Chem. Inc.).

\section{Immunohistochemistry}

Paraffin-embedded rat and human pancreas tissue were deparaffinized and blocked in a 1\% BSA/PBS solution for $1 \mathrm{~h}$ at room temperature. Sections were incubated with a 1:200 dilution of primary antibody for $1 \mathrm{~h}$. They were washed twice in $1 \times$ PBS for $10 \mathrm{~min}$ and incubated in a 1:500 dilution of biotinylated goat anti-rabbit $\mathrm{IgG}$ followed by a 30-min incubation in a 1:200 dilution of alkaline phosphatase streptavidin. Vector Red (Vector Laboratories, Burlingame, CA, USA) was used to visualize the binding of the primary antibodies. Sections were counterstained with hematoxylin (Fisher Scientific, Fairlawn, NJ, USA) using standard methods.

\section{Protein electrophoresis}

Proteins were run on NuPage gels (Invitrogen) and immunoblotted as previously described (Chessler et al. 2002). For quantitation, immunoblots were incubated with ECL-Plus chemiluminescent substrate (Amersham Biosciences, Piscataway, NJ, USA) and directly analyzed using a Molecular Dynamics Storm 840 imager and ImageQuant software (Amersham). Otherwise, blots were incubated with ECL substrate (Amersham) and the chemiluminescent signal captured by XAR film (Kodak, Rochester, NY, USA).

Two-dimensional (2-D) electrophoresis was performed according to the method of O'Farrell (1975) by Kendrick Labs, Inc. (Madison, WI, USA). To enhance the solubility of membrane proteins, islet samples were prepared in SDS boiling buffer (Ames \& Nikaido 1976). No urea was added to the sample buffer, and samples were kept frozen at $-80^{\circ} \mathrm{C}$, avoiding any risk of carbamylation (McCarthy et al. 2003). Isoelectric focusing was carried out in glass tubes using $2 \% \mathrm{pH}$ 3.5-10 ampholines (Amersham). After equilibration, the tube gels were sealed to stacking gels on top of $8 \%$ acrylamide slab gels for SDS-PAGE. Two 2-D gels were run in parallel: one with $200 \mu \mathrm{g}$ islet extract, which was analyzed after Western transfer to polyvinylidene fluoride membrane, and another with $10 \mu \mathrm{l}$ radiolabeled VIAAT spiked into $200 \mu \mathrm{g}$ islet extract, which was analyzed by autoradiography (using a storage phosphor screen) and phosphorimaging with a Storm 840 imager. A tropomyosin marker was added to each sample, and molecular weight markers (Sigma) were also run in the second dimension. Tropomyosin yields a characteristic pattern of spots which was observed in all 2-D gels run. To allow precise alignment of the resulting images, the western blot and the gel used for autoradiography were both stained with Coomassie blue to allow visualization and alignment of islet and marker proteins. Alignment was performed electronically using scanned images.

\section{Statistical analysis}

Data are presented as means \pm S.E. Differences between quantitative data sets were analyzed by one-way ANOVA. $P<0 \cdot 05$ was considered significant.

\section{Results}

\section{Synthesis and stability of VIAAT}

In vitro transcription and translation of VIAAT cDNA yields significant quantities of two proteins: V52 and V57. Parallel reactions with GAD67, GAD65, luciferase and Saccharomyces cerevisiae $\alpha$-factor cDNAs, in contrast, yielded significant amounts only of the expected protein: the appearance of a prominent, lower molecular weight protein was unique to VIAAT (Chessler et al. 2002 and data not shown). To verify that V52 does not result from proteolytic degradation, the time-course of V52 and V57 synthesis was analyzed (Fig. 1A). In repeated experiments, we consistently found that V52 and V57 appeared simultaneously: accumulation of V52 was not preceded by accumulation of V57. Furthermore, the amount of $\mathrm{V} 52$ relative to $\mathrm{V} 57$ did not increase over time, as would be expected if V57 were gradually converted to V52.

We also investigated the relative stability of both proteins in islet cell extracts, both to test for evidence of proteolytic activity that converts V57 to V52 and also to ensure that V52 is not formed as an artefact of islet cell lysis. We lysed isolated islets in both ionic (SDS) and non-ionic (1\% NP-40) detergent solutions both with and 


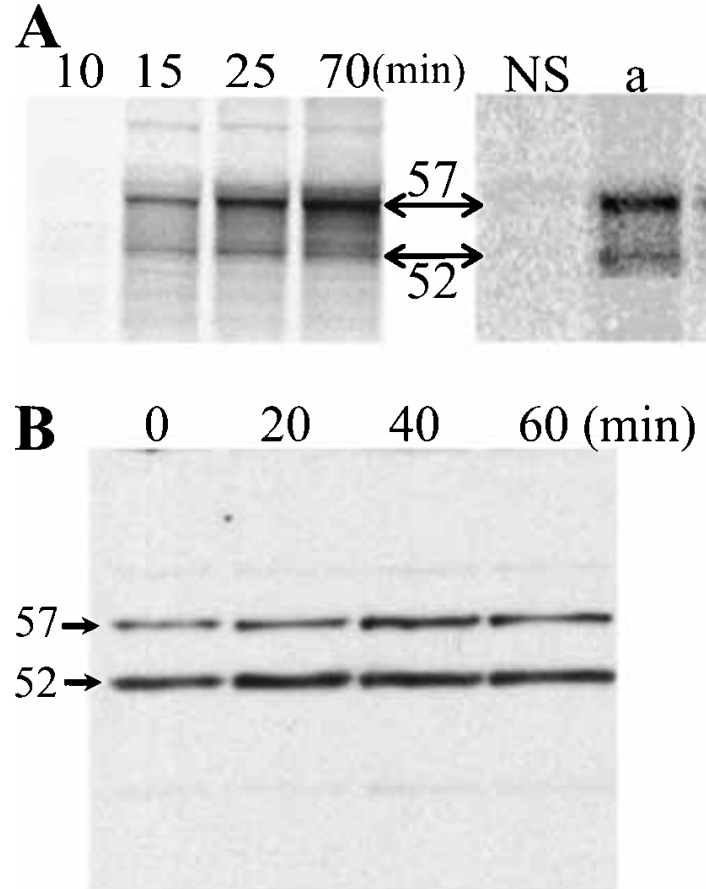

Figure 1 Synthesis and stability of V57 and V52. (A) VIAAT cDNA was added to an in vitro, reticulocyte lysate expression system containing ${ }^{35}$ S-methionine(time 0 ). Aliquots of the reaction mix were withdrawn at the times indicated above the lanes (left panel), and radiolabeled proteins were analyzed by SDS-PAGE and autoradiography. V52 and V57 appeared simultaneously $15 \mathrm{~min}$ after the addition of the VIAAT cDNA to the reticulocyte lysate, and there was no increase over time in the ratio of V52:V57. Immunoprecipitation of the reaction mixture after 70 min (right panel) with two different anti-VIAAT antibodies, VT/510 (lane a) and VT/75 (lane b), verified that the bands running at $57 \mathrm{kDa}$ and $52 \mathrm{kDa}$ were isoforms of VIAAT. A control immunoprecipitation was also performed with normal rabbit serum (NS). (B) Islet proteins were extracted in NP-40 lysis buffer without addition of protease inhibitors and incubated at $37^{\circ} \mathrm{C}$ for the amount of time indicated. V52 and V57 protein content was analyzed by immunoblotting with antibody VT/510. Both isoforms are stable in the lysis buffer. In experiments such as this with both non-ionic and ionic (SDS) detergent buffers and both with and without protease inhibitors, there was no evidence of conversion of V57 to V52.

without addition of protease inhibitors. Each type of lysis buffer performed equally well in extracting V52 and V57 from purified islets (data not shown). The lysates were incubated at $4{ }^{\circ} \mathrm{C}$ or $37^{\circ} \mathrm{C}$ and aliquots were withdrawn at set time-points. To determine whether there was an increase with time in the ratio of V52 to V57, which would be consistent with post-lysis conversion of V57 to the smaller isoform, the VIAAT content of the islet extract samples was examined by immunoblotting. One such experiment is depicted in Fig. 1B. A similar approach was used by Bedet et al. (2000) to demonstrate that V57' (a phosphorylated form

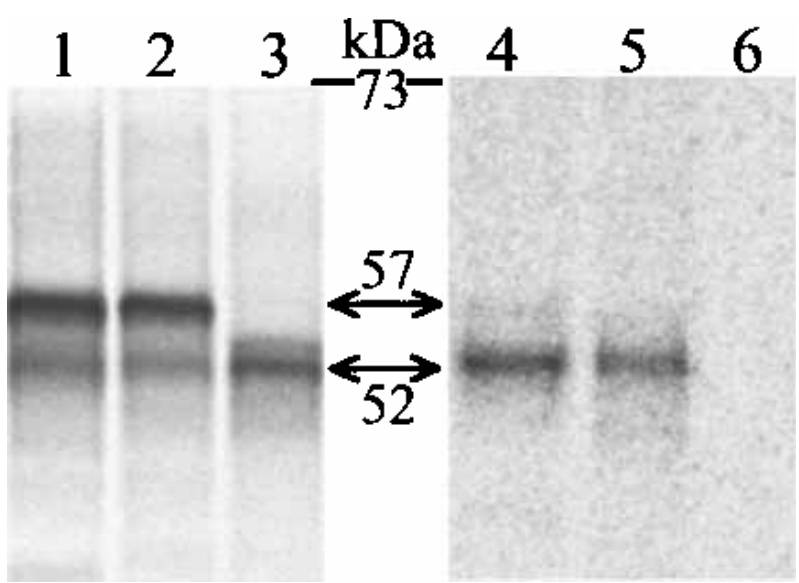

Figure 2 VIAAT synthesis from mutated cDNA templates. (Lanes 1-3) VIAAT (lane 1), VIAAT M31 L (lane 2) and VIAAT M1T (lane 3) were synthesized in rabbit reticulocyte lysates in the presence of ${ }^{35} \mathrm{~S}$-methionine[q;8] and analyzed by SDS-PAGE and autoradiography. As seen in lane 3, mutation of the initiator methionine (M1T) suppressed synthesis of V57 but not V52. (Lanes 4-6) To ensure that an isoform of VIAAT was synthesized from the M1T template despite mutation of the initiator codon, the $\mathrm{M} 1 \mathrm{~T}$ reaction product was immunoprecipitated with two anti-VIAAT antibodies, VT/510 (lane 4) and VT/75 (lane5). The $52 \mathrm{kDa}$ protein yielded by the M1T template was recognized by both antibodies. Normal rabbit serum was used as a control for non-specific binding (lane 6).

of V57) is gradually converted to V57 in brain extracts. In contrast, V57 was not converted into V52: there was no evidence of an increase in $\mathrm{V} 52$ content at the expense of V57 content during incubation at either $4{ }^{\circ} \mathrm{C}$ or $37^{\circ} \mathrm{C}$ in either type of detergent lysis buffer. The same result was obtained when radiolabeled, in vitro-translated VIAAT was incubated in islet extracts and then analyzed by autoradiography (data not shown).

\section{The VIAAT gene contains an alternate start site of translation}

To test whether synthesis of V52 could be due to the utilization of an alternate, downstream start site of translation, we analyzed VIAAT protein expression after mutating the V57 initiator codon (V57-M1T). As shown in Fig. 2, V52 was preferentially translated after mutation of VIAAT codon 1.

The ATG codon encoding methionine residue 31 occurs in a region of high homology to the eukaryotic consensus sequence for translation initiation (Kozak 1999) and is thus a candidate for an alternate translation start site. While alteration of this downstream codon suppressed synthesis of V52, the degree of suppression was, for unclear reasons, inconsistent (Fig. 2 and data not shown). As expected, the $\mathrm{M}>\mathrm{L}$ substitution at residue 31 did not affect synthesis of V57. 


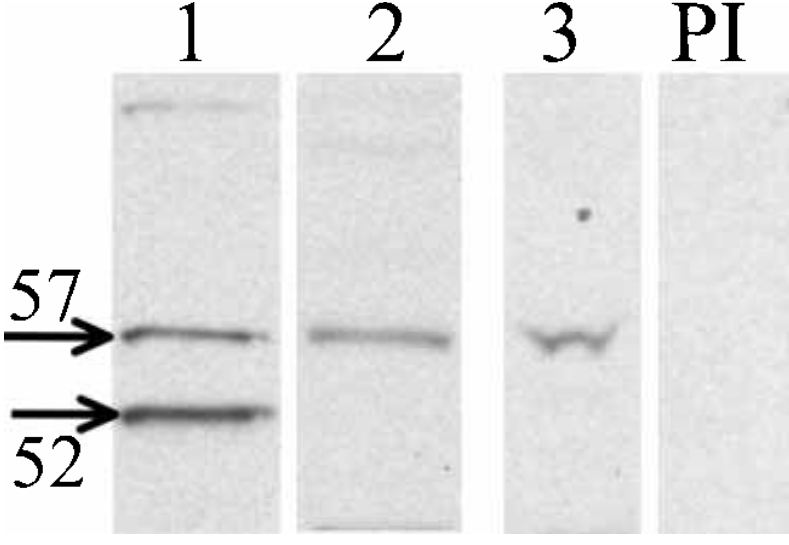

Figure 3 Immunorecognition of V57 and V52 by antibodies to the amino and carboxyl termini of VIAAT. (Lanes 1 and 2) A rat islet extract was immunoblotted with antibodies to the carboxyl terminus (VT/510, lane 1) and to the amino terminus (VT/17, lane 2) of VIAAT. (Lanes 3 and 4) Immunoblots of a rat brain extract using antibody VT/17 (lane 3) and preimmune serum from the same rabbit (PI). VT/17 exhibits specific recognition of V57 but does not bind V52. Detection of V52 by the carboxyl-terminal antibody (VT/510; lane 1, lower band) but not the amino-terminal antibody (VT/17; lanes 2 and 3) shows that V52's lower molecular weight (compared with V57) is attributable to an amino-terminal truncation.

The formation of V52 by utilization of a downstream start site of translation and the recognition of this protein by an antibody to the carboxyl terminus of VIAAT suggests that it is truncated at its amino-terminal end relative to V57. To confirm this, western blots of islet extracts were probed with an antibody to VIAAT residues 17-30 (VT/17). Consistent with the hypothesis that the two VIAAT variants differ at their amino-terminal ends, VT/17 recognized V57 but not V52 (Fig. 3).

To isolate $\mathrm{V} 52$, we introduced a $6 \mathrm{xHis}$ tag on the carboxyl terminus of V57-M1T. V52-6 xHis was preferentially translated from this construct and could be captured on nickel agarose beads (not shown). This confirmed that the carboxyl terminus of VIAAT is intact in V52 (since the 6 xHis tag remained functional). Captured V52-6 xHis was sent for amino-terminal sequencing. Sequencing, however, was unsuccessful, perhaps due to N-terminal blockage, a common problem with eukaryotic proteins (Brown \& Roberts 1976, Persson et al. 1985).

\section{2-D gel analysis of V52 and V57}

In order to analyze the pattern of post-translational modification of islet VIAAT and to confirm the identity of in vitro synthesized V52, VIAAT was detected by immunoblotting rat islet proteins separated using 2-D non-equilibrium $\mathrm{pH}$ gradient electrophoresis (NEPHGE)/SDS-PAGE (O'Farrell 1975). As seen in
Fig. 4, islet V57 runs as a 'train' of five to eight spots. This indicates that post-translational modifications result in multiple forms, but does not indicate the specific nature of the modifications. In contrast, islet V52 appears only as a single spot.

To verify that islet V52 and the reticulocyte lysate-derived V52 synthesized after mutation of codon 1 are the same, we asked whether they would co-migrate during 2-D electrophoresis. Radiolabeled V52 was prepared in the reticulocyte lysate system, spiked into islet extract and loaded onto a 2-D gel. This gel was run in parallel with the gel used to create the immunoblot shown in Fig. 4. The spots yielded by the radiolabeled V52 (Fig. 4Pi) aligned with the immunoblot at the positions indicated (Fig. 4A). As shown in Fig. 4A, the pattern of modification undergone by V52 synthesized in rabbit reticulocyte lysates was similar to that of islet-derived V57, with the protein separating into five forms in the same pI range as V57. We previously observed that bands representing V52 protein derived from islet and brain extracts and from in vitro synthesis co-migrate by SDS-PAGE (Chessler et al. 2002). In the present study, we found that reticulocyte lysate-derived $\mathrm{V} 52$, in the case of the form with the most acidic pI, precisely co-migrates with rat islet V52 during 2-D electrophoresis, suggesting that they are identical (Fig. 4A). Though membrane proteins can be well resolved during NEPHGE/SDS-PAGE, variable protein loss is a common problem and likely explains what, in Fig. 4, appears to be a greater abundance of V57 than V52 (Ames \& Nikaido 1976, Chevallet et al. 1998, Santoni et al. 2000).

The 2-D gel results showed V57 to consist of a heterogeneous group of differentially modified VIAAT molecules (Fig. 4A and B). Some of this heterogeneity was also apparent on standard 1-D gels, with brain-derived V57 frequently seen to migrate as a doublet: V57 and V57' (Bedet et al. 2000, Chessler et al. 2002). We previously showed that this differential modification results in differential detection of V57 by antibodies, likely due to specific modifications masking targeted epitopes (Chessler et al. 2002). VT/510, for example, does not detect human brain V57 or V57' on western blots (Chessler et al. 2002). Differential recognition of differently modified forms of V57 is probably the reason why the pattern of V57 spots seen with VT/75 and VT/510 varies (Fig. 4A and B). Differing detection of $\mathrm{V} 57$ by different antibodies is also seen in Fig. 4D, with VT/75 preferentially binding more slowly migrating forms in brain extracts (lanes 1 and 2) as compared with VT/510 (lanes 3 and 4).

\section{Differential regulation of V52 and V57 expression}

Levels of VIAAT expression in the brain have been reported to be responsive to agonists and antagonists of 

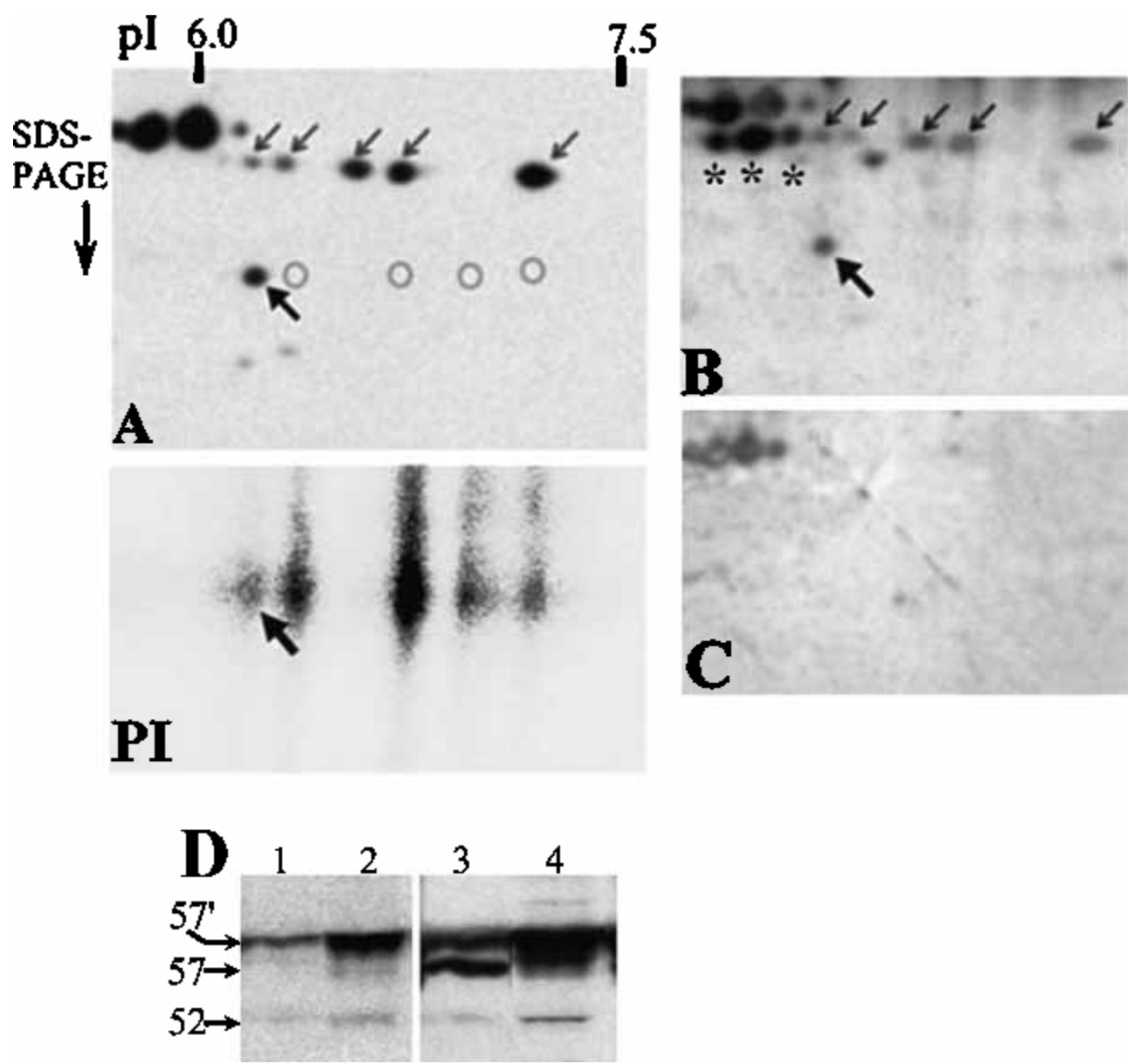

Figure 4 2-D electrophoresis of VIAAT. Two NEPHGE/SDS-PAGE gels were run in parallel to analyze proteins from rat islets (by immunoblotting) and radiolabeled V52 synthesized in vitro using a VIAAT cDNA construct with a mutated initiator codon. (A) Immunoblot analysis of the rat islet extract using antibody VT/510. V57 separated into a train of five spots (small arrows), indicating that there are at least five differentially modified forms of the protein. V52, in contrast, migrated as one spot (larger, bold arrow). $\mathrm{Pi}$, in vitro synthesized, radiolabeled V52 was spiked into islet extract and run in parallel on a separate 2-D gel. It also separated into five differentially modified species. The phosphorimage (Pi) was aligned with the immunoblot $(\mathrm{A})$ as described in Materials and methods to allow direct comparison of the spots generated by in vitro synthesis with those derived from the islet extract. One of the five VIAAT species detected by phosphorimaging precisely co-migrated with endogenous islet V52 (indicated by the bold arrow). The other four forms ran where indicated by the circles drawn on the immunoblot. (B) The immunoblotted membrane was stripped and probed with a second anti-VIAAT antibody, VT/75. The spots depicted by the five small arrows and one large arrow co-migrate with the spots shown in (A). VT/75 also detected what are likely three additional V57 species (marked by asterisks) with more acidic pl values. (C) The immunoblotted membrane was stripped and probed with normal rabbit serum. The four spots present in the upper left-hand corner of this panel and $(A)$ and (B) likely represent non-specific antibody binding. (D) Immunoblot of rat brain extract (lanes 1 and 3) and rat brain synaptic vesicle preparation (lanes 2 and 4) with VT/75 (lanes 1 and 2) and VT/510 (lanes 3 and 4). As in (A) and (B), different patterns of recognition of V57 species can be seen depending on which antibody is used. For example, in lane 1, VT/75 can be seen to preferentially detect a more slowly migrating form (V57').

presynaptic $\mathrm{GABA}_{\mathrm{B}}$ receptors, to ethanol and to antipsychotic medications (Kang et al. 2003, Zink et al. 2004, Zink \& Spanagel 2005). Since, in the pancreatic islets, GAD65 and GAD67 expression and GABA release are subject to metabolic regulation, we hypothesized that islet VIAAT content may be similarly regulated (Hao et al. 1994, Smismans et al. 1997, Petersen et al. 1998). We therefore investigated VIAAT expression after islet exposure to different glycemic conditions. Rat islets were equilibrated overnight in 

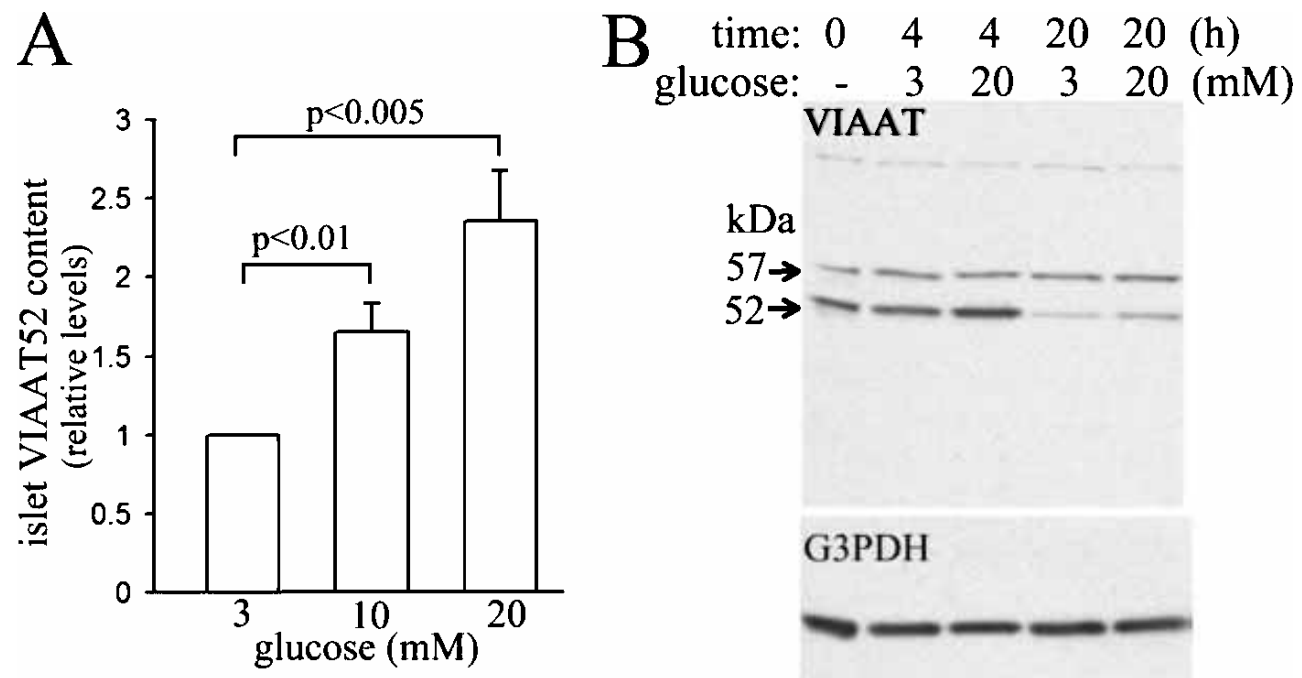

Figure 5 Effects of glucose concentration on islet VIAAT content. (A) Islets were isolated and allowed to equilibrate overnight in RPMI. Equal numbers of islets were then cultured separately at the glucose concentrations indicated, and V52 and V57 content was analyzed by immunoblotting with VT/510 and VT/75. Islet V57 content did not vary with glycemic conditions. V52 content varied as shown (levels shown are relative to V52 content at $3 \mathrm{mmol} / \mathrm{l}$ glucose; $n=6 ; P>0.05$ for the difference between the $10 \mathrm{mmol} / \mathrm{l}$ and $20 \mathrm{mmol} / \mathrm{l}$ glucose datasets). (B) We noted that islet V52 content decreased over $20 \mathrm{~h}$ after newly isolated islets were placed in culture. To test the effect of glucose on the decline in V52 levels during this initial 20-h period, newly isolated islets were cultured for 4 or $20 \mathrm{~h}$ after purification as indicated above each lane or lysed immediately after isolation ( $0 \mathrm{~h}$, left-most lane). The culture media contained either 3 or $20 \mathrm{mM}$ glucose, as indicated. After 4 or $20 \mathrm{~h}$ in culture media, the islets were harvested and lysed. VIAAT content in the resulting extracts was analyzed by immunoblotting. A representative experiment is shown. As previously noted, V52 content fell after the newly purified islets had been in culture for $20 \mathrm{~h}$. Higher glucose concentrations attenuated this decrease. After $4 \mathrm{~h}$, V52 content was $56 \%( \pm 7 \%)$ greater in the islets cultured at $20 \mathrm{mmol} / \mathrm{l}$ glucose, and, after $20 \mathrm{~h}, \mathrm{~V} 52$ content was $41( \pm 5 \%)$ greater at the higher glucose level $(n=5, P<0.05$ for both). In contrast to V52 content, content of V57 and glyceraldehyde 3-phosphate dehydrogenase (G3 PDH) did not change significantly in response to removal of islets from the pancreatic to the tissue culture environments or in response to glycemic conditions. Note also that there was also no change in the protein apparent as a background band above the two VIAAT bands.

standard RPMI and then cultured for $20 \mathrm{~h}$ in different glucose concentrations. Afterwards, islet VIAAT content was examined by immunoblot analysis (Fig. 5A). V57 content did not vary in response to media glucose concentration. V52 levels, however, increased in response to higher glucose levels. Consistent with previous published results (Hao et al. 1994, Petersen $e t$ al. 1998), levels of GAD67 - the form of GAD present, along with VIAAT, in the islet mantle - were also observed to increase (data not shown).

Unexpectedly, we noted that V52 levels decreased relative to V57 levels during the overnight period of equilibration in RPMI medium immediately following islet isolation. The extent of decline was variable, and V52 levels reached their nadir - 15-30\% of 4-h culture levels - by $20 \mathrm{~h}$ (Fig. 5B and data not shown). Elevated glucose concentrations significantly attenuated but did not prevent the fall in V52 content: after $4 \mathrm{~h}$, V52 content was $56 \%( \pm 7 \%)$ greater in islets cultured at
$20 \mathrm{mmol} / \mathrm{l}$ glucose than in islets cultured in $3 \mathrm{mmol} / \mathrm{l}$ glucose, and, after $20 \mathrm{~h}, \mathrm{~V} 52$ content was $41 \%$ ( $\pm 5 \%$ ) greater at the higher glucose level $(n=5, P<0.05$ for both; see Fig 5B). In contrast, V57 and glyceraldehyde 3-phosphate dehydrogenase levels did not change (Fig. 5B). During the initial 20-h period of equilibration in culture media after islet isolation, then, a higher glucose concentration resulted in less of a decline in V52 content (as in Fig. 5B), but the overall effect of glucose on V52 content was less than in experiments performed after the islets had been allowed to equilibrate in culture medium overnight (as in Fig. 5A).

\section{VIAAT expression in INS- 1 and islet $\beta$ cells}

Conflicting results have been published concerning whether VIAAT is expressed in $\beta$ cells (Chessler et al. 2002, Hayashi et al. 2003a, Gammelsaeter et al. 2004). Immunoblot analysis showed that the rat $\beta$ cell line 

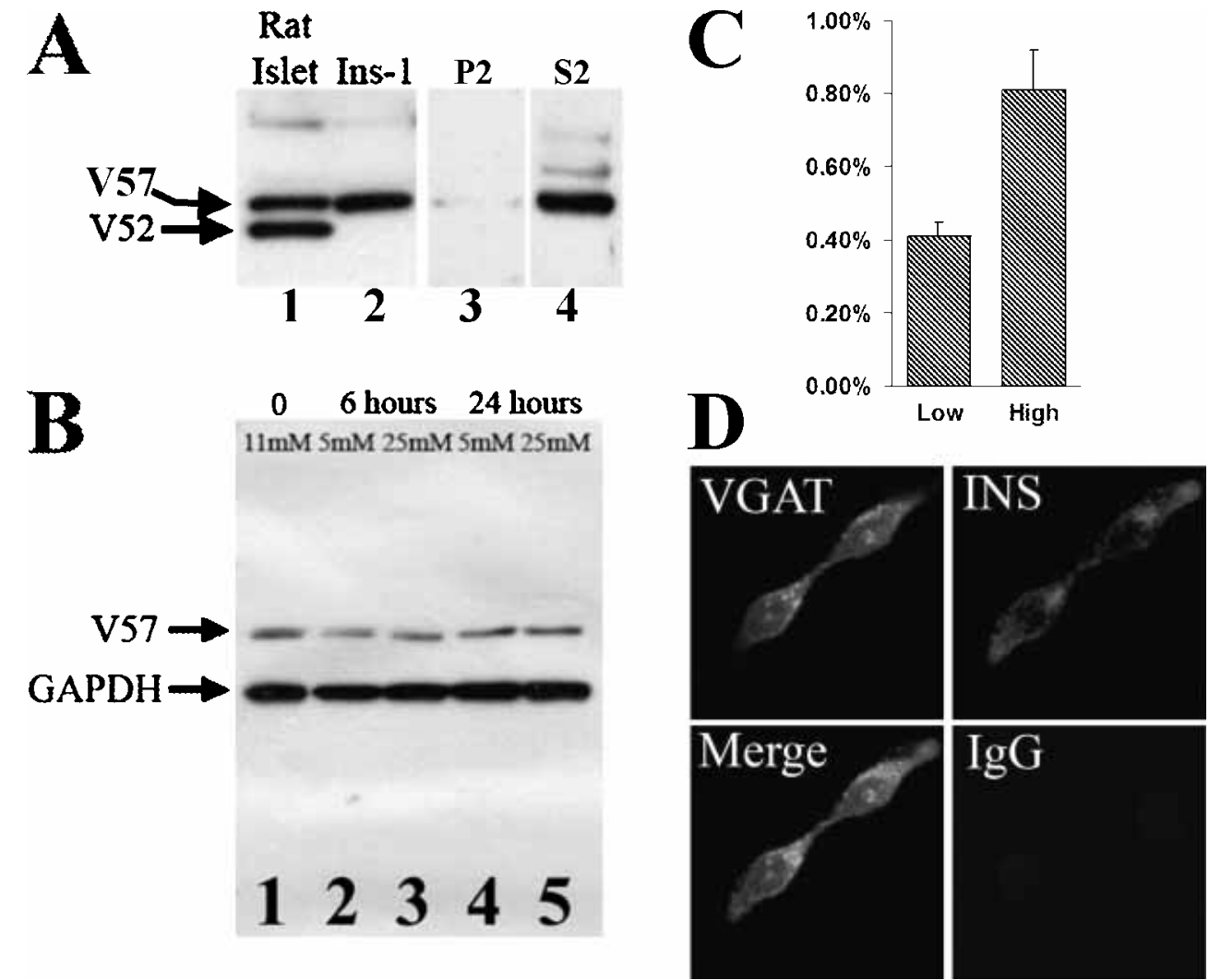

Figure 6 VIAAT expression in the $\beta$ cell line INS-1. (A) Immunoblot of extracts prepared from rat islets (lane 1) and INS-1 cells (lane 2) using antibody VT/510. INS-1 cells express VIAAT, but only V57 and not V52. After INS-1 cell fractionation, V57 was detected in S2 (lane 4), consistent with its presence in synaptic-like microvesicles. VIAAT is also detected in P2 (lane 3) which contains the other membranous compartments, such as endosomes and secretory granules, separated from the microvesicles during the high-speed centrifugation. (B) INS-1 cells were either maintained in $11 \mathrm{mM}$ glucose (lane 1) or switched $6 \mathrm{~h}$ (lanes 2 and 3) or $24 \mathrm{~h}$ (lanes 4 and 5) before being harvested into medium with $5 \mathrm{mM}$ (lanes 2 and 4) or $25 \mathrm{mM}$ (lanes 3 and 5) glucose. Equal amounts of extracted proteins were analyzed by SDS-PAGE with antibody VT/510. V57 content did not change in response to changes in glucose concentration. As a control for protein loading, the blot was simultaneously probed with an antibody to glyceraldehyde-3-phosphate dehydrogenase (GAPDH). (C) In parallel with the experiment shown in (B), insulin secretion was assessed in INS-1 cells cultured in low glucose $(2.5 \mathrm{mM})$ or high glucose $(25 \mathrm{mM})$ for $2 \mathrm{~h}$. Secretion is shown as a percent of total cellular insulin content ( $n=12, P<0.001$ for the difference between low and high glucose). (D) INS-1 cells were immunostained for insulin (INS, red) and VIAAT (with VT/510; VGAT, green). The merged image shows that VIAAT and insulin do not co-localize. Control staining of INS-1 cells (panel labeled IgG) with non-immune IgG revealed no non-specific immunofluorescent signal.

INS-1 expressed V57 but not V52, consistent with $\beta$ cell expression of at least one form of the transporter (Fig. 6A) (Poitout et al. 1996).

Gammelsaeter et al. (2004) presented evidence that VIAAT localizes to synaptic-like microvesicles (SLMVs) in $\beta$ cells. To test whether VIAAT also associates with SLMVs in INS-1 cells, cells were fractionated as described in Materials and methods to yield a high-speed supernatant S2 containing microvesicles and depleted of secretory granules and endosomes (Clift-O'Grady et al. 1998). S2 contained VIAAT (Fig. 6A); this demonstrates its presence in SLMVs but does not exclude that it is also present in secretory granules (Clift-O'Grady et al. 1990, 1998). Detection of microvesicular proteins in $\mathrm{P} 2$ in addition to $\mathrm{S} 2$ is typical due to their passage through other, larger membranous compartments, such as endosomes, during sorting. Because of this, detection of VIAAT in P2, as seen, is not informative as to whether VIAAT is also present in secretory granules (Fig. 6A). V57 content in INS-1 cells did not change in response to glycemic conditions (Fig. 6B); this was in contrast to insulin secretion, which was tested in parallel (Fig. 6C). Immunofluorescent staining revealed that INS-1 cells uniformly expressed 

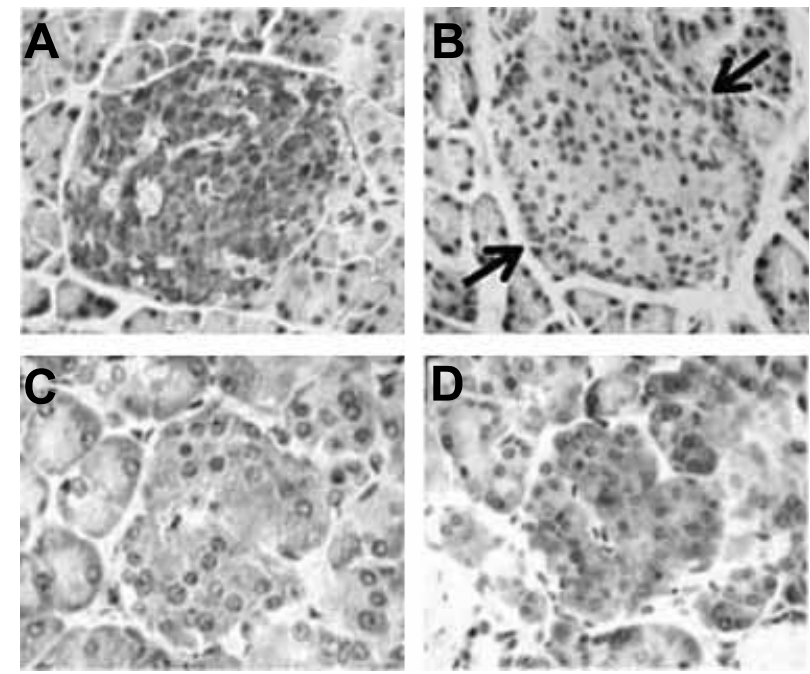

Figure 7 Immunostaining of rat and human pancreas sections. (A and C) VIAAT was detected in $(A)$ rat and $(C)$ human islets using antibody VT/75. In contrast to antibody VT/510, which previously yielded weak staining of the islet core ( $\beta$ cell region), with VT/75, detection of VIAAT in the islet core was readily apparent. These results were reproducible using a monoclonal antibody (M-VT/75) targeted to the same VIAAT peptide. (D) Human pancreatic tissue stained using M-VT/75. (B)

Non-immune rabbit lgG was used in the same concentration as $\mathrm{VT} / 75$ as a control for non-specific staining. A representative rat islet (between arrows) stained with control IgG is shown.

both insulin and VIAAT (Fig. 6D). Consistent with trafficking of the transporter to microvesicles in INS-1 cells, VIAAT and insulin did not co-localize (Fig. 6D). The intranuclear staining seen with VT/510 was likely an artifact of cell fixation such as has been previously described (Chang et al. 1996, Wieczorek et al. 1997, Miller 2001).

Antibody VT/510 previously yielded relatively weak staining of the rat islet core ( $\beta$ cell region) compared with the mantle (Chessler et al. 2002). Because VT/75 displays a different pattern of recognition of the modified forms of V57 and because it has been proven to be an effective antibody for immunohistochemistry in a variety of settings (see, for example: Geigerseder et al. 2003, Prange et al. 2004, Ghih et al. 2005, Saito et al. 2005), we used it to stain rat and human pancreas sections (Fig. 7). VT/75 made staining of the rat islet core readily apparent and enabled detection of VIAAT in human islets for the first time (Fig. 7A and $\mathrm{C}$ ). These results were reproducible with $\mathrm{M}-\mathrm{VT} / 510$, a monoclonal antibody made against the same peptide (for an example see Fig. 7D).

\section{Discussion}

Islet cells likely evolved from an ancestral neuronal precursor and have inherited a diverse set of proteins that, in the central nervous system, provide the machinery for cell-to-cell signaling across synapses (Donev 1984, Regoli et al. 2000, Rulifson et al. 2002). These proteins include GAD65, GAD67, GABA receptors, glutamate and glycine receptors and vesicular glutamate and GABA transporters (Satin \& Kinard 1998, Chessler et al. 2002, Hayashi et al. 2003b, Gammelsaeter et al. 2004). It is highly likely that, in the islet, these proteins are similarly constituents of intercellular signaling mechanisms. Continued characterization of the islet neurotransmitter signaling apparatus will be important for eventually understanding islet paracrine and autocrine signaling and the means by which islet function is co-ordinated at the cellular level.

Here, we have followed up on our prior work demonstrating that rat islets contain VIAAT, including a heretofore unidentified $52.5 \mathrm{kDa}$ variant: V52. We have now identified V52 as an isoform of VIAAT that likely results from translation initiation at an alternate, downstream start site. V52 is subject to a different pattern of post-translational modifications than V57. Cellular V52 content is regulated independently of V57 content and is responsive to changes in glucose concentration. V52 content is affected as well by other, extracellular conditions, since basal levels changed during islet culture regardless of glycemic conditions. V57, we found, is subjected to a complex pattern of post-translational modifications. These modifications result in formation of a doublet, V57 and V57', seen on Western blots, with $\mathrm{V} 57^{\prime}$ being most evident in brain extracts (Bedet et al. 2000). The true heterogeneity of post-translationally modified V57, however, is only apparent after 2-D electrophoresis which, we have shown, reveals approximately five to eight differentially modified species.

It is clear that, in the rabbit reticulocyte lysate system, V52 is synthesized as a result of utilization of an alternate initiator codon. This mechanism for formation of multiple protein products from the same gene, while not common, has been observed with a variety of other eukaryotic genes (for example, see references in: Barraille et al. 1999, O’Donovan \& Baraban 1999, Liu et al. 2000, Byrd et al. 2002). Rat islet V52 and in vitro synthesized V52 co-migrate by SDS-PAGE and by 2-D NEPHGE/SDS-PAGE, suggesting that they are identical and that they are thus formed by the same mechanism of downstream translational initiation. It is also possible that V52 is formed in islets by proteolytic cleavage during post-translational processing. In this case, the identical (or nearly identical) localization of an alternate initiation codon and a proteolytic cleavage site would have to be attributed to an unlikely coincidence. No evidence of a proteolytic activity that converts V57 to V52 was detected in rat islet extracts. Since antibody VT/17 binds only V57 while VT/75 binds both V52 and $\mathrm{V} 57$, the site of the amino-terminal truncation that 
results in V52 must lie between the binding sites of the two antibodies. These reside between VIAAT residues 17-30 for $\mathrm{VT} / 17$ and between residues 75-87 for $\mathrm{VT} / 75$.

In the central nervous system, VIAAT traffics to synaptic vesicles and may associate with GAD65 (Jin et al. 2003). In islet $\alpha$ cells, GAD65 is absent, and the trafficking pattern of VIAAT is different, as the protein ends up associated predominantly with secretory granules (Hayashi et al. 2003b). It is possible that - as a result of truncation of VIAAT's cytoplasmic aminoterminal domain - V52 is better adapted to the different pathway of intracellular sorting and protein complex formation that is perhaps followed by VIAAT in the islet $\alpha$ cells. Here we have shown that, in rat islet extracts, up to eight species of modified V57 but only one of V52 are detected by 2-D NEPHGE/SDS-PAGE. Further work is needed to more fully characterize the sorting and post-translational modification pathways of the two isoforms.

Ebihara et al. (2003) have reported that mouse neurons synthesize a VIAAT splice variant with a unique carboxyl-terminal sequence. This splice variation, like the truncation that produces V52, affects the cytoplasmic region of the protein (McIntire et al. 1997, Ebihara et al. 2003). While the mouse VIAAT coding region spans three exons, the exon structure of the rat VIAAT gene is identical to the human exon structure: the amino-terminal 130 residues are encoded by one exon and the remaining 395 residues by a second (Chessler et al. 2002, Ebihara et al. 2003). In the absence of an exon-intron structure amenable to minor splice variations, as in the mouse, utilization of alternate initiator codons provides a different means for modification of the cytoplasmic region of VIAAT in rat and human cells. Others have presented evidence that protein expression can be regulated in this manner and have proposed mechanisms (Barraille et al. 1999, O’Donovan \& Baraban 1999, Liu et al. 2000, Byrd et al. 2002).

Immunohistochemistry with antibody VT/510 suggested that rat islet $\beta$ cells contain VIAAT (Chessler et al. 2002). Results published subsequently have been conflicting (Hayashi et al. 2003a, Gammelsaeter et al. 2004). The immunostaining results shown herein provide further evidence of $\beta$ cell expression of VIAAT. We also found that INS-1 cells contain V57 but not V52. This result is consistent with the presence of VIAAT in the islet $\beta$ cells and suggests that V52 may be limited to the $\alpha$ cells. The mechanism whereby V52 expression is suppressed in INS-1 cells remains to be determined. Regulation may occur at the level of translation, as has been described with other proteins formed from alternative start sites or, alternatively, there may be increased turnover of V52 in INS-1 cells (Barraille et al. 1999, Liu et al. 2000, Byrd et al. 2002).
The islet GAD-GABA system is subject to metabolic regulation. Levels of GAD65 and GAD67 expression and of GABA release vary in response to glycemic conditions (Hao et al. 1994, Smismans et al. 1997, Petersen et al. 1998). This suggests that GABA signaling may play a role in co-ordinating islet function to maintain euglycemia. Glycine likely plays a similar role (Gammelsaeter et al. 2004). Unlike neurons or islet $\beta$ cells, rat $\alpha$ cells contain only GAD67: GAD65 is absent. This unique feature of the mantle GAD-GABA system has important implications, as it limits the means by which GABA signaling can be regulated. Unlike GAD65, which is highly regulated, both by association/ dissociation with an essential cofactor and by phosphorylation, GAD67 activity is not actively regulated, and the enzyme is, in essence, constitutively active (Lernmark 1996, Battaglioli et al. 2003). We therefore hypothesized that regulation of $\alpha$ cell VIAAT content could provide an important means by which to regulate GABA release. Regulation of VIAAT levels would similarly be expected to modulate islet cell glycine release. Since GABA levels are markedly lower in rat $\alpha$ cells than in $\beta$ cells, regulation of glycinergic signaling may be particularly relevant to $\alpha$ cell function (Gammelsaeter et al. 2004).

Our results have shown that cellular V52 content increases with glucose concentration. Interestingly, the $\alpha$ cell content of vesicular glutamate transporter (VGLUT) is affected by glycemic conditions in the opposite direction (Bai et al. 2003). Glutamate is an excitatory neurotransmitter and, like VIAAT, $\alpha$ cell VGLUT is secretory granule associated (Hayashi et al. 2003b). It is possible, therefore, that as glucose concentrations rise, $\alpha$ cells secrete relatively more GABA and glycine and less glutamate. Besides glycemic conditions, other metabolic or intercellular signals play an important role in determining islet V52, but not V57, content, as levels of the smaller isoform dropped after islets were removed from their native environment and placed in tissue culture. Regulation of cellular VIAAT content is not unique to islet cells, as neuronal VIAAT content responds markedly to agonists and antagonists of presynaptic $\mathrm{GABA}_{\mathrm{B}}$ receptors, ethanol and antipsychotic medications (Kang et al. 2003, Zink et al. 2004, Zink \& Spanagel 2005).

In summary, we have identified a novel isoform of VIAAT, V52, a variant of the transporter truncated within the cytoplasmic, amino-terminal domain. V52 is abundant in rat islets. In reticulocyte lysates, VIAAT cDNA directs the synthesis of both V52 and V57 as a result of utilization of alternate start sites of translation, and islet V52 is likely formed by the same mechanism. Post-translationally, V52 traverses a different pathway of processing and, perhaps, sorting than V57. Islet-derived V57, unlike V52, displays a complex pattern of post-translational modifications. By immunostaining 
pancreas sections, we confirmed prior reports that VIAAT is present in islet $\beta$ cells and detected the protein in both rat and human islets. We also found that the $\beta$ cell line INS- 1 expresses VIAAT, but only in the form of V57. Islet content of V52, but not of V57, increases in response to higher glucose concentrations. This is consistent with prior results indicating that the islet GAD-GABA system is responsive to metabolic stimuli. This sensitivity to metabolic stimuli, in turn, suggests that GABAergic and probably also glycinergic signaling help to co-ordinate the endocrine functioning of the islet.

\section{Acknowledgements}

Islet isolations were performed by the University of Washington Diabetes and Endocrinology Research Center (DERC) Islet Cell and Functional Analysis Core (DK17047). We thank Victor Faundez and Branch Craige for their expert assistance with INS-1 cell fractionation and Angela Wallen and Eric DeJulio for assistance with islet isolation and culture. The DERC Molecular Genetics Core assisted with cDNA cloning and sequencing. This research was funded by grants to S D C from the National Institutes of Health (K08-DK02944 and DK065877). We thank Åke Lernmark for his encouragement and advice. The authors declare that there is no conflict of interest that would prejudice the impartiality of this scientific work.

\section{References}

Ames GF \& Nikaido K 1976 Two-dimensional gel electrophoresis of membrane proteins. Biochemistry 15 616-623.

Bai L, Zhang X \& Ghishan FK 2003 Characterization of vesicular glutamate transporter in pancreatic alpha- and beta-cells and its regulation by glucose. American Fournal of Physiology, Gastrointestinal and Liver Physiology 284 G808-G814.

Barraille P, Chinestra P, Bayard F \& Faye JC 1999 Alternative initiation of translation accounts for a $67 / 45 \mathrm{kDa}$ dimorphism of the human estrogen receptor ERalpha. Biochemistry and Biophysics Research Communications 257 84-88.

Battaglioli G, Liu H \& Martin DL 2003 Kinetic differences between the isoforms of glutamate decarboxylase: implications for the regulation of GABA synthesis. Fournal of Neurochemistry $\mathbf{8 6}$ 879-887.

Bedet C, Isambert MF, Henry JP \& Gasnier B 2000 Constitutive phosphorylation of the vesicular inhibitory amino acid transporter in rat central nervous system. Fournal of Neurochemistry $\mathbf{7 5}$ $1654-1663$

Bieg S, Koike G, Jiang J, Klaff L, Pettersson A, MacMurray AJ, Jacob HJ, Lander ES \& Lernmark A 1998 Genetic isolation of iddm 1 on chromosome 4 in the biobreeding (BB) rat. Mammalian Genome 9 324-326.

Braun M, Wendt A, Buschard K, Salehi A, Sewing S, Gromada J \& Rorsman P 2004a GABAB receptor activation inhibits exocytosis in rat pancreatic beta-cells by G-protein-dependent activation of calcineurin. Fournal of Physiology 559 397-409.

Braun M, Wendt A, Birnir B, Broman J, Eliasson L, Galvanovskis J, Gromada J, Mulder H \& Rorsman P $2004 b$ Regulated exocytosis of GABA-containing synaptic-like microvesicles in pancreatic beta-cells. Fournal of General Physiology 123 191-204.

Brown JL \& Roberts WK 1976 Evidence that approximately eighty per cent of the soluble proteins from Ehrlich ascites cells are Nalpha-acetylated. Fournal of Biological Chemistry 251 1009-1014.

Byrd MP, Zamora M \& Lloyd RE 2002 Generation of multiple isoforms of eukaryotic translation initiation factor 4 GI by use of alternate translation initiation codons. Molecular and Cellular Biology 22 4499-4511.

Chang KL, Arber DA \& Weiss LM 1996 CD20: A review. Applied Immunohistochemistry 4 1-15.

Chessler SD \& Lernmark A 2000 The role of glutamic acid decarboxylase and GABA in the pancreas and diabetes. In $G A B A$ in the Nervous System: The View at Fifty Years, pp 471-484. Eds DL Martin \& RW Olson. Philadelphia: Lippincott Williams \& Wilkins.

Chessler SD, Simonson WT, Sweet IR \& Hammerle LP 2002 Expression of the vesicular inhibitory amino acid transporter in pancreatic islet cells: distribution of the transporter within rat islets. Diabetes 51 1763-1771.

Chevallet M, Santoni V, Poinas A, Rouquie D, Fuchs A, Kieffer S, Rossignol M, Lunardi J, Garin J \& Rabilloud T 1998 New zwitterionic detergents improve the analysis of membrane proteins by two-dimensional electrophoresis. Electrophoresis 19 1901-1909.

Chih B, Engelman H \& Scheiffele P 2005 Control of excitatory and inhibitory synapse formation by neuroligins. Science $\mathbf{3 0 7}$ $1324-1328$

Clift-O'Grady L, Linstedt AD, Lowe AW, Grote E \& Kelly RB 1990 Biogenesis of synaptic vesicle-like structures in a pheochromocytoma cell line PC-12. Fournal of Cell Biology 110 1693-1703.

Clift-O'Grady L, Desnos C, Lichtenstein Y, Faundez V, Horng JT \& Kelly RB 1998 Reconstitution of synaptic vesicle biogenesis from PC12 cell membranes. Methods 16 150-159.

Dickson LM, Lingohr MK, McCuaig J, Hugl SR, Snow L, Kahn BB, Myers MG Jr \& Rhodes CJ 2001 Differential activation of protein kinase $\mathrm{B}$ and $\mathrm{p} 70(\mathrm{~S} 6) \mathrm{K}$ by glucose and insulin-like growth factor 1 in pancreatic beta-cells (INS-1). Fournal of Biological Chemistry 276 21110-21120.

Donev SR 1984 Ultrastructural evidence for the presence of a glial sheath investing the islets of Langerhans in the pancreas of mammals. Cell and Tissue Research 237 343-348.

Dumoulin A, Rostaing P, Bedet C, Levi S, Isambert MF, Henry JP, Triller A \& Gasnier B 1999 Presence of the vesicular inhibitory amino acid transporter in GABAergic and glycinergic synaptic terminal boutons. Fournal of Cell Science 112 811-823.

Ebihara S, Obata K \& Yanagawa Y 2003 Mouse vesicular GABA transporter gene: genomic organization, transcriptional regulation and chromosomal localization. Molecular Brain Research 110 126-139.

Echigo N \& Moriyama Y 2004 Vesicular inhibitory amino acid transporter is expressed in gamma-aminobutyric acid (GABA)-containing astrocytes in rat pineal glands. Neuroscience Letters 367 79-84.

Elliott JF, Qin HY, Bhatti S, Smith DK, Singh RK, Dillon T, Lauzon J \& Singh B 1994 Immunization with the larger isoform of mouse glutamic acid decarboxylase (GAD67) prevents autoimmune diabetes in NOD mice. Diabetes 43 1494-1499.

Gammelsaeter R, Froyland M, Aragon C, Danbolt NC, Fortin D, Storm-Mathisen J, Davanger S \& Gundersen V 2004 Glycine, GABA and their transporters in pancreatic islets of Langerhans: evidence for a paracrine transmitter interplay. Fournal of Cell Science $1173749-3758$.

Gasnier B 2004 The SLC32 transporter, a key protein for the synaptic release of inhibitory amino acids. Pflugers Archiv $\mathbf{4 4 7}$ 756-759.

Geigerseder C, Doepner R, Thalhammer A, Frungieri MB, Gamel-Didelon K, Calandra RS, Kohn FM \& Mayerhofer A 
2003 Evidence for a GABAergic system in rodent and human testis: local GABA production and GABA receptors. Neuroendocrinology 77 314-323.

Hampe CS, Lundgren P, Daniels TL, Hammerle LP, Marcovina SM \& Lernmark A 2001 A novel monoclonal antibody specific for the N-terminal end of GAD65. Fournal of Neuroimmunology 113 63-71.

Hao W, Li L, Mehta V, Lernmark A \& Palmer JP 1994 Functional state of the beta cell affects expression of both forms of glutamic acid decarboxylase. Pancreas 9 558-562.

Hayashi M, Otsuka M, Morimoto R, Muroyama A, Uehara S, Yamamoto A \& Moriyama Y 2003a Vesicular inhibitory amino acid transporter is present in glucagon-containing secretory granules in alphaTC6 cells, mouse clonal alpha-cells, and alpha-cells of islets of Langerhans. Diabetes 52 2066-2074.

Hayashi M, Yamada H, Uehara S, Morimoto R, Muroyama A, Yatsushiro S, Takeda J, Yamamoto A \& Moriyama Y $2003 b$ Secretory granule-mediated co-secretion of L-glutamate and glucagon triggers glutamatergic signal transmission in islets of Langerhans. Fournal of Biological Chemistry 278 1966-1974.

Jin H, Wu H, Osterhaus G, Wei J, Davis K, Sha D, Floor E, Hsu CC, Kopke RD \& Wu JY 2003 Demonstration of functional coupling between gamma -aminobutyric acid (GABA) synthesis and vesicular GABA transport into synaptic vesicles. PNAS 100 4293-4298.

Kang TC, Park SK, Hwang IK, An SJ \& Won MH 2003 Presynaptic gamma-aminobutyric acid type B receptor-mediated regulation of vesicular gamma-aminobutyric acid transporter expression in the gerbil hippocampus. Neuroscience Letters 346 49-52.

Kozak M 1999 Initiation of translation in prokaryotes and eukaryotes. Gene 234 187-208.

Lernmark A 1996 Glutamic acid decarboxylase - gene to antigen to disease. Fournal of Internal Medicine 240 259-277.

Lingohr MK, Dickson LM, Wrede CE, Briaud I, McCuaig JF, Myers MG Jr \& Rhodes CJ 2003 Decreasing IRS-2 expression in pancreatic beta-cells (INS-1) promotes apoptosis, which can be compensated for by introduction of IRS-4 expression. Molecular and Cellular Endocrinology 209 17-31.

Liu J, Prolla G, Rostagno A, Chiarle R, Feiner H \& Inghirami G 2000 Initiation of translation from a downstream in-frame AUG codon on BRCAl can generate the novel isoform protein DeltaBRCA1(17aa). Oncogene 19 2767-2773.

McCarthy J, Hopwood F, Oxley D, Laver M, Castagna A, Righetti PG, Williams K \& Herbert B 2003 Carbamylation of proteins in 2-D electrophoresis - myth or reality? Foumal of Proteome Research 2 239-242.

McIntire SL, Reimer RJ, Schuske K, Edwards RH \& Jorgensen EM 1997 Identification and characterization of the vesicular GABA transporter. Nature 389 870-876.

Miller RT 2001 Technical Immunohistochemistry: Achieving Reliability and Reproducibility of Immunostains, pp 1-53. Dallas: Society for Applied Immunohistochemistry.

O’Donovan KJ \& Baraban JM 1999 Major Egr3 isoforms are generated via alternate translation start sites and differ in their abilities to activate transcription. Molecular and Cellular Biology 19 4711-4718.

O'Farrell PH 1975 High resolution two-dimensional electrophoresis of proteins. Fournal of Biological Chemistry 250 4007-4021.

Persson B, Flinta C, von Heijne G \& Jornvall H 1985 Structures of $\mathrm{N}$-terminally acetylated proteins. European Fournal of Biochemistry $152523-527$.

Petersen JS, Rimvall K, Jorgensen PN, Hasselager E, Moody A, Hejnaes K, Clausen JT \& Dyrberg T 1998 Regulation of GAD expression in rat pancreatic islets and brain by gamma-vinyl-GABA and glucose. Diabetologia 41 530-535.

Poitout V, Olson LK \& Robertson RP 1996 Insulin-secreting cell lines: classification, characteristics and potential applications. Diabetes Metabolism 22 7-14.

Prange O, Wong TP, Gerrow K, Wang YT \& El-Husseini A 2004 A balance between excitatory and inhibitory synapses is controlled by PSD-95 and neuroligin. PNAS 101 13915-13920.

Regoli M, Orazioli D, Gerli R \& Bertelli E 2000 Glial fibrillary acidic protein (GFAP)-like immunoreactivity in rat endocrine pancreas. Foumal of Histochemistry and Cytochemistry 48 259-266.

Rulifson EJ, Kim SK \& Nusse R 2002 Ablation of insulin-producing neurons in flies: growth and diabetic phenotypes. Science 296 $1118-1120$.

Saito T, Iwata N, Tsubuki S, Takaki Y, Takano J, Huang SM, Suemoto T, Higuchi M \& Saido TC 2005 Somatostatin regulates brain amyloid beta peptide Abeta42 through modulation of proteolytic degradation. Nature Medicine 11434439.

Santoni V, Molloy M \& Rabilloud T 2000 Membrane proteins and proteomics: un amour impossible? Electrophoresis 21 1054-1070.

Satin LS \& Kinard TA 1998 Neurotransmitters and their receptors in the islets of Langerhans of the pancreas: what messages do acetylcholine, glutamate, and GABA transmit? Endocrine 8 213-223.

Smismans A, Schuit F \& Pipeleers D 1997 Nutrient regulation of gamma-aminobutyric acid release from islet beta cells. Diabetologia 40 1411-1415.

Solimena M 1998 Vesicular autoantigens of type 1 diabetes. Diabetes/Metabolism Revieres 14 227-240.

Sweet IR, Cook DL, DeJulio E, Wallen AR, Khalil G, Callis J \& Reems J 2004 Regulation of ATP/ADP in pancreatic islets. Diabetes 53 401-409.

Sweet IR, Cook DL, Wiseman RW, Greenbaum CJ, Lernmark A, Matsumoto S, Teague JC \& Krohn KA 2002 Dynamic perifusion to maintain and assess isolated pancreatic islets. Diabetes Technology Therapy 4 67-76.

Takamori S, Riedel D \& Jahn R 2000 Immunoisolation of GABA-specific synaptic vesicles defines a functionally distinct subset of synaptic vesicles. Foumal of Neuroscience $204904-4911$.

Wieczorek R, Stover R \& Sebenik M 1997 Nonspecific nuclear immunoreactivity after antigen retrieval using acidic or basic solutions. Fournal of Histotechnology 20 139-143.

Wrede CE, Dickson LM, Lingohr MK, Briaud I \& Rhodes CJ 2002 Protein kinase B/Akt prevents fatty acid-induced apoptosis in pancreatic beta-cells (INS-1). Fournal of Biological Chemistry 277 49676-49684.

Wrede CE, Dickson LM, Lingohr MK, Briaud I \& Rhodes CJ 2003 Fatty acid and phorbol ester-mediated interference of mitogenic signaling via novel protein kinase $\mathrm{C}$ isoforms in pancreatic beta-cells (INS-1). Fournal of Molecular Endocrinology 30 271-286.

Zink M \& Spanagel R 2005 Ethanol induces GAD67 and VGAT in slice cultures of newborn rat cerebral cortex. Neuroreport $\mathbf{1 6}$ 377-380.

Zink M, Schmitt A, May B, Muller B, Braus DF \& Henn FA 2004 Differential effects of long-term treatment with clozapine or haloperidol on GABA transporter expression. Pharmacopsychiatry 37 $171-174$.

Received 15 September 2005

Accepted 28 October 2005

Made available online as an Accepted Preprint 18 November 2005 